\title{
Las políticas de memoria democrática en España: entre la impunidad y las obligaciones internacionales
}

\author{
Manuel Sánchez-Moreno ${ }^{1}$
}

Recibido: 03/02/2020 / Aceptado: 28/03/2020

Resumen. Desde el inicio de la Transición a la democracia en España, se han venido produciendo una serie de medidas de reparación dirigidas a las víctimas de la guerra civil. Con una democracia más consolidada y favorecidas por los gobiernos de izquierda, se han ido ampliando estas leyes, condenando al franquismo y reivindicando a la II República. Sin embargo, la democracia española está aún lejos de alcanzar los estándares internacionales y los reclamos sociales en materia de memoria democrática. Como objetivo vamos a analizar estas leyes estatales desde 1976 hasta nuestros días, viendo su evolución y siguiendo una metodología cualitativa de análisis de contenidos. Palabras clave: Memoria histórica y democrática, justicia transicional, España, franquismo.

\section{[en] The politics of democratic memory in Spain: between impunity and international obligations}

\begin{abstract}
Since the beginning of the Transition to democracy in Spain, a series of reparation measures have been taking place aimed at victims of the civil war. With a more consolidated democracy and favoured by left-wing governments, these laws have been expanded, condemning Francoism and vindicating the Second Republic. However, Spanish democracy is still far from reaching international standards and social demands regarding democratic memory. Our objective is to analyze these state laws from 1976 to the present day, seeing their evolution and following a qualitative methodology of content analysis.
\end{abstract}

Keywords: Historical and Democratic Memory, Transitional Justice, Spain, Francoism.

Sumario. 1. Introducción. 2. Las recomendaciones internacionales a España en materia de memoria. 3. Primeras medidas y medidas durante el gobierno de la Unión de Centro Democrático (1976-1982). 4. Las medidas durante la presidencia de Felipe González (19821996). 5. Las medidas durante la presidencia de José María Aznar (1996-2004). 6. Las medidas durante la presidencia de José Luis Rodríguez Zapatero (2004-2011). 7. Las medidas durante la presidencia de Mariano Rajoy (2011-2018). 8. Los nuevos gobiernos de izquierda desde 2018. 9. Conclusiones.

Cómo citar: Sánchez-Moreno, M. (2020): Las políticas de memoria democrática en España: entre la impunidad y las obligaciones internacionales, en Cuadernos de Gobierno y Administración Pública 7-1, 41-52.

Para Chato Galante (1948-2020), siempre en nuestra memoria.

Me sirve tu batalla sin medalla. Me sirve la modestia de tu orgullo posible y tu mano segura sí me sirve. Me sirve tu sendero compañero. (Benedetti)

\section{Introducción}

La Sentencia n ${ }^{\circ}$ 101/2012 de la Sala de lo Penal del Tribunal Supremo, declaró la imposibilidad legal de investigar en los tribunales españoles los crímenes de la gue- rra civil y la dictadura franquista. Reconoce sin más que la Transición fue una "impunidad absoluta con indemnización a las víctimas", dejando claro que las medidas reparatorias eran las económicas como una manera de "derecho transicional" y obviando el pacto de élites. En base a este consenso "sacralizado" no cabe réplica jurídica (Sánchez-Moreno, 2019a: 285).

Esta falta de conocimiento e interpretación histórica es equiparable a la falta de consideración de la impunidad jurídica y de la supremacía de la imprescriptibilidad de los crímenes de lesa humanidad, en un constante esfuerzo por justificar el soft law al que obliga el derecho internacional de los derechos humanos, la irretroacti-

\footnotetext{
Universidad Complutense de Madrid

mansan11@ucm.es
} 
vidad de leyes y la tipificación interna de delitos. Esta visión del "derecho transicional" evidentemente no contempla la "justicia transicional" en sentido procedimental y en sentido global. La misma decisión confirma jurídicamente la legitimidad del franquismo del que emanó la democracia en España.

Hay una voluntad jurídica amnética que interpreta la legislación desde este sentido equidistante, obviando la lectura de la historia y la llave que está en la misma Ley 46/1977 de Amnistía para desarrollar una justicia anamnética basada en el sufrimiento de las víctimas y sus familiares (Mate, 2011: 229). Una tendencia que también podemos aplicar a gran parte de las leyes de memoria emanadas desde la administración central del Estado.

Como objetivo vamos a analizar estas leyes estatales desde 1976 hasta nuestros días siguiendo una metodología cualitativa de análisis de contenidos, en este caso de legislación e informes que se irán citando en el texto, limitando el uso de fuentes secundarias. Insistimos en que analizaremos sólo leyes estatales y no las de carácter autonómico y local, que extenderían mucho el artículo. La bibliografía es deliberadamente parca, para potenciar un análisis sin sesgos previos y centrado en la normativa. El enfoque de esta metodología parte de la teoría crítica de los derechos humanos, que legitima a las víctimas en sus luchas (Sánchez-Moreno, 2019b).

Pero ¿de qué hablamos cuando abordamos la memoria histórica? Paloma Aguilar (1996: 41) la define como "la 'memoria prestada' de acontecimientos del pasado que el sujeto no ha experimentado personalmente" (1996: 41). En ella está muy presente la tensión entre los dos elementos básicos de esta memoria: el recuerdo y el olvido. Cuando este pasado alude a conflictos armados que desestabilizan o interrumpen una democracia, o a regímenes no democráticos que derrocan gobiernos legítimos, hablamos más específicamente de "memoria democrática", que aquí usamos enlazada a la histórica.

Por su lado, la CIDH (Comisión Interamericana de Derechos Humanos) en los Principios sobre Politicas Públicas de Memoria en las Américas entiende por políticas públicas de memoria "a las distintas intervenciones, sustentadas en evidencia documental y testimonial, y forjadas con la participación de las víctimas y sociedad civil, que se encuentran abocadas al reconocimiento estatal de los hechos y de su responsabilidad por las graves violaciones a los derechos humanos ocurridas, la reivindicación y conservación de la memoria y dignidad de las víctimas, la difusión y preservación de la memoria histórica y a la promoción de una cultura de derechos humanos y democracia orientada a la no repetición de los hechos"'.

Estas políticas se basan en el Informe Joinet de Naciones Unidas (1997), en cuyo anexo II define la justicia transicional como "las situaciones al término de las cuales, en el marco de un proceso que da lugar a un diálogo nacional en favor de la democracia o a negociaciones de paz para poner fin a un conflicto armado, se llega a

Principios sobre Políticas Públicas de Memoria en las Américas. Resolución 3/2019. Disponible en: https://www.oas.org/es/cidh/decisiones/pdf/Resolucion-3-19-es.pdf [Consulta: 15 de marzo de 2020]. un acuerdo, sea cual fuere su forma, en virtud del cual los protagonistas o las partes interesadas se entienden para tomar, en ese momento, medidas contra la impunidad y la repetición de las violaciones de los derechos humanos"3.

Estas medidas contra la impunidad, es decir, políticas de memoria, deben ser guiadas por cuatro derechos. La verdad como deber de recordar y establecer los hechos mediante comisiones extrajudiciales de investigación o comisiones de verdad, y preservación de archivos relacionados con las violaciones de derechos humanos. La justicia para investigar las violaciones, perseguir a sus autores y, si se establece su culpabilidad, hacer que sean sancionados. El derecho a obtener reparación con medidas de restitución (cuyo objetivo debe ser lograr que la víctima recupere la situación en la que se encontraba antes); medidas de indemnización (que cubran los daños y perjuicios físicos y morales, así como la pérdida de oportunidades, los daños materiales, los ataques a la reputación y los gastos de asistencia jurídica); medidas de rehabilitación (atención médica y psicológica o psiquiátrica); y medidas simbólicas, de reparación moral, como el reconocimiento público y solemne por el Estado de su responsabilidad, las declaraciones oficiales de restablecimiento de la dignidad de las víctimas, los actos conmemorativos, monumentos, etc. Y finalmente las garantías de no repetición, como disolución de grupos; derogación de todas las disposiciones de excepción, legislativas o de otra índole; y separación del cargo de los altos funcionarios implicados en las violaciones graves que se hayan cometido.

Como hemos dicho, nuestro análisis comienza en plena Transición española, en 1976, y este es un informe de 1997. Sin embargo, estas medidas se llevaban aplicando mucho antes, y ante la consideración de los crímenes franquistas como crímenes de lesa humanidad, los aspectos temporales no funcionan, ya que se puede aplicar la retroactividad. Además, esto tiene relación con los procesos de justicia postransicional. Cuando durante las transiciones a la democracia no se pueden aplicar las medidas anteriormente mencionadas, es posible una revisión posterior, cuando la democracia está más asentada. Ambos casos, se dan en España.

\section{Las recomendaciones internacionales a España en materia de memoria}

Las Naciones Unidas a través de sus mecanismos convencionales y extraconvencionales de protección de derechos humanos insisten sobre las responsabilidades de España ante estas cuestiones. Durante 2019 y 2020 España se está sometiendo a su III Examen Periódico Universal, donde ya ha informado de algunas medidas legislativas que está llevando a cabo. Aún no hay un re-

\footnotetext{
La cuestión de la impunidad de los autores de violaciones de los derechos humanos (civiles y políticos). Informe final elaborado y revisado por M. Joinet en aplicación de la decisión 1996/119 de la Subcomisión. E/CN. 4/Sub. 2/1997/20/Rev.1. Disponible en: https:// undocs.org/es/E/CN.4/Sub.2/1997/20/Rev.1 [Consulta: 15 de marzo de 2020].
} 
sultado a este examen, pero la posición de España no varía mucho respecto a exámenes anteriores. Esta posición se basa en la ley 52/2007 de memoria histórica y otras proposiciones legales, como la ley de bebés robados que veremos seguidamente y la sacralidad de la Transición y su ley de Amnistía de 1977, cerrando cualquier proceso penal. Este hecho fomenta la impunidad, contraviniendo los estándares internacionales de derechos humanos y los propios principios de justicia transicional como hemos visto.

La Oficina del Alto Comisionado de las Naciones Unidas para los Derechos Humanos en consonancia con asociaciones memorialistas y de derechos humanos, insiste en que España debe elaborar un plan nacional de búsqueda de personas desaparecidas durante la guerra civil y el franquismo, exhumación e identificación de víctimas, crear una comisión de la verdad, avances judiciales con responsabilidades penales, y reparación a las víctimas. A pesar de estas faltas, en este último examen periódico se pueden ver avances, impulsados por el gobierno socialista. El anterior periodo de revisión (2015) estuvo tocado por la crisis económica y especialmente por la falta de voluntad política del Partido Popular (PP), ${ }_{4}^{4}$ que prácticamente no propone medidas.

A la espera también del último informe del Relator Especial sobre la promoción de la verdad, la justicia, la reparación y las garantías, podemos detenernos en su estudio de 2014. Destaca que hay una gran brecha entre las posiciones de las instituciones del Estado y de las víctimas y asociaciones; siendo estas últimas las que han impulsado las mayores medidas. Subraya la necesidad de establecer un mecanismo que esclarezca la verdad, eliminación o resignificación de símbolos y monumentos franquistas, establecer una educación histórica fundamentada en los derechos humanos, fortalecer la formación del funcionariado, incluido el poder judicial y las fuerzas de seguridad en derechos humanos y memoria histórica. Respecto a la reparación: ampliar la cobertura para incluir a víctimas que han quedado fuera incluyendo la restitución documental y de propiedades a particulares; hacer efectiva la nulidad de sentencias durante la Guerra Civil y el franquismo; y propone ampliar los estudios existentes sobre las violaciones a los derechos de las mujeres. Respecto a la Justicia: privar de efecto las disposiciones de la Ley de Amnistía que obstaculizan todas las investigaciones y el acceso a la justicia; asumir e implementar las obligaciones internacionales; y colaborar con procesos judiciales en el exterior, así como fomentar la justicia universal.

Ese mismo año, España emite su informe sobre estos comentarios, ${ }^{5}$ destacando en el párrafo 7 que la "tran-

El PP, así refundado en 1989 es la antigua Alianza Popular. Constituido en partido político desde 1976 por algunos ministros y personas cercanas al dictador Francisco Franco como Manuel Fraga. El otro partido que surgió el régimen fue la Unión de Centro Democrático (UCD), fundado en 1977

5 Informe del Relator Especial sobre la promoción de la verdad, la justicia, la reparación y las garantías de no repetición, Pablo de Greiff. Misión a España: Comentarios del Estado al informe del Relator Especial (2014). Disponible en: https://documents-dds-ny.un.org/ doc/UNDOC/GEN/G14/163/59/PDF/G1416359.pdf?OpenElement [Consulta: 15 de marzo de 2020]. sición española constituye un caso único de reconciliación nacional sin justicia penal, por decisión deliberada y consensuada por la inmensa mayoría de las fuerzas políticas parlamentarias de evitar la justicia transicional. El equilibrio entre los distintos intereses, paz y democracia, justicia y reconciliación, se encontró en España a costa de renunciar a la justicia penal. Los derechos de las víctimas fueron inicialmente relegados, pero desde los inicios de la democracia empezaron a adoptarse medidas de reconocimiento y reparación que culminaron con la adopción de la conocida como Ley de Memoria Histórica en 2007." En el párrafo 10, se afirma que este marco consensuado se hizo durante la Ley de Amnistía de 1977 y los jueces "no hacen sino aplicar los principios de legalidad y de irretroactividad de la ley penal, pilares del Estado de Derecho."

Teniendo como referencia los compromisos internacionales de España en materia de derechos humanos, y los que está dispuesta a llevar a cabo, veremos cómo van evolucionando las políticas de memoria en base a los distintos gobiernos.

\section{Primeras medidas y medidas durante el gobierno de la Unión de Centro Democrático (1976-1982)}

En estos primeros momentos tras la muerte del dictador Francisco Franco y antes de la Constitución, primaba la metodología establecida por el presidente de las cortes franquistas Torcuato Fernández Miranda, que proponía una transición, yendo "de la Ley a la Ley", evitando la ruptura política, administrativa y jurídica de una Transición que se quedó en una transmisión. De este modo se podrían atenuar las susceptibilidades del franquismo y se verían los deseados cambios democráticos reclamados por la Plataforma de Organismos Democráticos (Muñoz de Córdoba, 2009: 455).

Esta "reforma en la continuidad" se basó en quitar yerro a la represión del régimen franquista defendiendo un "franquismo sociológico" (Juliá, 1999: 215). Existía un "gatopardismo" mediante el cual es necesario que algo cambie para que las estructuras de poder de las clases dominantes sigan igual. Uno de sus representantes era el presidente del gobierno, Arias Navarro que finalmente dimitió, nombrando el rey a Adolfo Suarez como presidente del gobierno (Ruiz, 2002: 30).

Durante 1976 se dictaron varias normativas con carácter de indulto y de compensación económica para las personas afectadas, especialmente por la Guerra Civil, que es el único acontecimiento que se considera realmente negativo, no así el franquismo. Nos encontramos con el Decreto 670/1976 de 5 de marzo, por el que se regulan pensiones a favor de los españoles que habiendo sufrido mutilación a causa de la pasada contienda no puedan integrarse en el Cuerpo de Caballeros Mutilados de Guerra por la Patria, una norma alusiva al bando vencido que no pudo integrarse en el citado Cuerpo.

En sucesivos decretos, la Amnistía de 1976 se ampliará a diversos sectores sindicales y del funcionariado. Se sanciona el Real Decreto-Ley 19/1977, de 14 de 
marzo, sobre medidas de gracia, que especifica que la amnistía de 1976 excluye delitos que "hubieran puesto en peligro o lesionado la vida o la integridad de las personas."

Tras la Amnistía de 1977, y ya plenamente con el gobierno de la UCD liderado por Suárez las medidas reparatorias tuvieron un carácter más extenso y específico por materias y grupos sociales, especialmente entre el bando vencido. El Real Decreto-ley 6/1978, de 6 de marzo, por el que se regula la situación de los militares que tomaron parte en la guerra civil, estableciendo beneficios económicos para ellos, viudas y huérfanos. Regulado por la Orden para la aplicación del Real Decretoley 6/1978, de 6 de marzo. El Real Decreto-ley 35/1978, de 16 de noviembre, por el que se conceden pensiones a los familiares de los españoles fallecidos como consecuencia de la guerra 1938-1939, ${ }^{6}$ que se aplica indistintamente del bando a los familiares de fallecidos durante la guerra civil.

El Real Decreto-ley 43/1978, de 21 de diciembre, por el que se reconocen beneficios económicos a los que sufrieron lesiones y mutilaciones en la Guerra Civil Española, incluyendo a la población civil, regulado por el Ministerio de Hacienda por la Orden de 9 de enero de 1979 y por la Orden del Ministerio del Interior de 24 de febrero de 1979. En 1979 continuaron las medidas de reparación vinculadas con la guerra civil, como la Ley 5/1979, de 18 de septiembre, sobre reconocimiento de pensiones, asistencia médico-farmacéutica y asistencia social en favor de las viudas, y demás familiares de los españoles fallecidos como consecuencia o con ocasión de la pasada guerra civil, que mejora los decretos anteriores sobre pensiones de afectados y sus familiares durante la guerra civil.

En todas ellas, la compensación de las mujeres es en tanto viudas, madres de huérfanos o hijas solteras. También, amplía el margen temporal a "después de la guerra", si murieron a consecuencia de heridas, fueron privados de libertad o desaparecidos a consecuencia de la guerra, según el artículo 1.2. En el artículo 3 establece pensiones vitalicias de viudedad, orfandad o a favor de familiares; asistencia médico-farmacéutica de las víctimas y asistencia social especialmente a personas de la tercera edad. La ley se regula con el Real Decreto 2635/1979, de 16 de noviembre y con la Resolución de la Dirección General del Tesoro de 27 de noviembre de 1979.

En 1980 se producen varias leyes interesantes en lo que se refiere a beneficios diferenciados para el bando republicano. Así, nos encontramos con la Ley 35/1980, de 26 de junio, sobre pensiones a los mutilados excombatientes de la zona republicana, mejorando y ampliando el Real Decreto-Ley 43/1978 y el Real Decreto-Ley 6/1978, dirigido a "hombres o mujeres combatientes o civiles, que sufrieron mutilaciones como consecuencia de la guerra". A pesar de esta especificación en el preámbulo, las retribuciones establecidas no ofrecen una diferencial por sexo.

\footnotetext{
Será derogado por la Ley 5/1979, de 18 de septiembre, que tendrá un carácter más extenso.
}

Finalmente es destacable en este año la Orden de 31 de julio de 1980 por la que se crea el Patronato de la Sección de Guerra Civil del Archivo Histórico Nacional, ${ }^{7}$ con sede en Salamanca para archivar, conservar y poner a disposición de la investigación documentación referente a la guerra civil española, que se había conservado durante el franquismo con fines represivos. Este archivo de origen franquista y que ahora se articula como centro de investigación histórico, se creó como un depósito de la documentación incautada a los "enemigos de la Patria", recopilando fuentes de la Oficina de Investigación y Propaganda Anticomunista (OIPA), la Delegación del Estado para la Recuperación de Documentos (DERD) y el Tribunal Especial para la Represión de la Masonería y el Comunismo.

En 1982 llegan las últimas leyes del gobierno de la UCD, en este caso bajo la presidencia de Leopoldo Calvo-Sotelo: el Real Decreto 391/1982, de 12 de febrero, por el que se integran en el Régimen General de la Seguridad Social, a efectos de asistencia sanitaria y servicios sociales, a los mutilados excombatientes de la zona republicana. Y la Ley 6/1982, de 29 de marzo, de pensiones a los mutilados civiles de guerra, que mejora las pensiones presentes en el Decreto 670/1976, actualizándose cada año.

\section{Las medidas durante la presidencia de Felipe González (1982-1996)}

Esta etapa del Partido Socialista Obrero Español (PSOE), profundizó en las reparaciones económicas precedentes, pero con un mayor reconocimiento del bando republicano y de las víctimas de la represión franquista, entre las que se encontraban socialistas. Entre otras destacamos la Ley 18/1984, de 8 de junio, sobre reconocimiento como años trabajados a efectos de la Seguridad Social de los periodos de prisión sufridos; y la Ley 37/1984 de 22 de octubre, de reconocimiento de derechos y servicios prestados a quienes durante la guerra civil formaron parte de las Fuerzas Armadas, Fuerzas de Orden Público y Cuerpos de Carabineros de la República.

Es destacable que durante este periodo se llevaron a cabo algunas que reformas que pretendían la democratización de algunos sectores, como defensa y seguridad. Es el caso de la Ley Orgánica 1/1984, sobre regulación de los criterios básicos de la defensa nacional y la organización militar; o la Ley Orgánica 2/1986, de 13 de marzo, de Fuerzas y Cuerpos de Seguridad. Reforma, pero no depuración, ya que se mantenían las jerarquías y se aseguraba la continuidad franquista. El único reconocimiento interesante desde la memoria democrática y justicia transicional es la Ley 24/1986, de rehabilitación de militares profesionales, incluyendo la Unión Militar Democrática. $^{8}$

Derogada por el Real Decreto 426/1999, de 12 de marzo, de creación del Archivo General de la Guerra Civil Española, pasando así a ser un archivo independiente.

8 Se refiere a los militares constituidos el 1 de septiembre de 1974 a favor de un cambio democrático, que fueron procesados y condenados quedando fuera de la Amnistía de 1977. 
Cabría preguntarse qué pasó con el sector de la justicia. Las medidas de democratización fueron igual de tímidas, como la Ley Orgánica 6/1985, de 1 de julio, del Poder Judicial, ${ }^{9}$ mediante la cual los jueces serán elegidos por las Cortes, vulnerando el principio de separación de poderes.

En 1990 se sigue avanzando con relación a las personas presas durante el franquismo con la Ley 4/1990, de 29 de junio sobre los Presupuestos Generales del Esta$d o$, en cuya disposición adicional decimoctava, establece una ampliación de las compensaciones por prisión, basándose en los supuestos contemplados en la Ley de Amnistía de 1977. En 1993 se vuelve a abordar el tema de la fuerte emigración que hubo durante la guerra civil y el franquismo en el Real Decreto 728/1993, de 14 de mayo, por el que se establecen pensiones asistenciales por ancianidad en favor de los emigrantes españoles.

Una norma más explícita con el bando republicano es el Real Decreto 39/1996, de 19 de enero, sobre concesión de la nacionalidad española a los combatientes de las Brigadas Internacionales en la guerra civil española. Las Brigadas Internacionales apoyaron expresamente al bando republicano y por primera vez, encontramos una legislación que reconoce indirectamente la legitimidad de la II República. Estas serían algunas de las pocas medidas de reparación simbólica ante las medidas económicas, insuficientes, irregulares e inequitativas que no contemplan los derechos integrales de las víctimas.

\section{Las medidas durante la presidencia de José María Aznar (1996-2004)}

Entendemos que hay cambios en la memoria histórica tras el triunfo del PP en las elecciones generales en 1996. Este periodo estará marcado por tres factores: la movilización social, el debilitamiento del pacto de silencio, trasunto de la impunidad, y la politización de la memoria. Siguiendo a Paloma Aguilar, el pacto de silencio se empieza a tambalear en 1993, cuando el gobierno socialista comienza a entrar en crisis y el PP se convierte en una amenaza real como líder de la oposición. Es entonces cuando la memoria se instrumentaliza y entra en los debates parlamentarios (Aguilar, 2006: 282-283; Aguilar, 2008: 86).

Es este el inicio de la postransición española. Desde la década de los 90 se visibilizan más las voces revisionistas del pasado reciente con motivo de los aniversarios de la II República y la Guerra Civil, que actúan como activadores de la memoria. Estas voces se fueron organizando formalmente y en el año 2000 se crean una serie de asociaciones memorialistas donde las víctimas o sus familiares empiezan a reclamar el derecho a la memoria en materia de justicia o de exhumaciones. De este año es la Asociación para la Recuperación de la Memoria Histórica (ARMH) o la Federación Estatal de Foros por la Memoria creada en 2004. Apoyándose en partidos de la oposición y en normativa europea e internacional en

Reformada parcialmente con la Ley Orgánica 2/2001, de 21 de junio. materia se cuestionan el consenso de la Transición y la Ley de Amnistía de 1977, manifestándose en contra de la inacción del Estado.

Hay dos únicas normativas de este periodo. Por un lado, la Ley 43/1998, de 15 de diciembre, de Restitución o Compensación a los Partidos Políticos de Bienes y Derechos Incautados en aplicación de la normativa sobre responsabilidades políticas del período 1936-1939. Para los partidos políticos ilegalizados durante el franquismo y no disueltos antes de 1995.

La otra medida es el Real Decreto 426/1999, de 12 de marzo, de creación del Archivo General de la Guerra Civil Española, dando salida a la petición que, la Junta Superior de Archivos hizo en noviembre de 1996, con el objetivo de que dejase de ser una sección del Archivo Histórico Nacional en Salamanca, tuviese en la misma ciudad entidad propia y "se reúna toda aquella documentación dispersa vinculada a aquel período de nuestro pasado", como afirma el preámbulo. También se menciona que el interés de este archivo es el de la investigación histórica y el de aportar documentación para la Ley 37/1984, de 22 de octubre, de Reconocimiento de Derechos y Servicios Prestados a quienes Durante la Guerra Civil Formaron Parte de las Fuerzas Armadas y de Orden Público y Cuerpo de Carabineros de la República. En base al artículo 7.1., dentro del archivo se creará el "Centro de Estudios y Documentación sobre la Guerra Civil Española para facilitar el mejor conocimiento de la misma y estimular la investigación histórica." De este modo se consagra la guerra civil como pasado histórico.

Pero sin duda el gobierno de Aznar sigue manteniendo otra memoria, la transmitida a través de la Transición. Se conceden una serie de subvenciones a la Fundación Nacional Francisco Franco (FNFF), constituida legalmente en 1976 para "la difusión de la memoria y obra de Francisco Franco". Entre 2000 y 2003 recibieron un total de 146.811,92 € para labores de microfilmación del archivo que tienen y que sólo es accesible parcialmente. A esto hay que sumar las subvenciones anuales que viene recibiendo el Valle de los Caídos, donde estaba sepultado Franco y sigue Primo de Rivera, oficiándose misas en su memoria. Así, en 2013 la Abadía recibió 340.000 $€$ "por levantar las cargas espirituales" y "atender a la finalidad social de la fundación" según el Tribunal de Cuentas. Efectivamente esta abadía benedictina fue fundada en 1940 por Franco para conmemorar su victoria, estableciendo una serie de obligaciones para su sustento, que siguen hasta hoy. ${ }^{10}$ Son ejemplos de otro tipo de políticas de memoria.

En este momento político reacio a volver sobre el pasado reciente de los vencidos, pero no de los vencedo-

10 Informe de fiscalización del organismo consejo de administración del Patrimonio Nacional. Ejercicio 2013. Disponible en: http:// www.tcu.es/tribunal-de-cuentas/.content/EnlacesBuscador/I1166 La FNFF han seguido recibiendo fondos hasta 2015, no hay información de años posteriores. Otras fundaciones susceptibles de recibir fondos públicos y que mantienen la memoria franquista son Fundación Las Hijas de Millán Astray y Capitán Cortés, la Fundación Yagüe, la Fundación Grupo de Estudios Estratégicos, la Fundación José Antonio Primo de Rivera, la Fundación Pro-Infancia Queipo de Llano, la Fundación Blas Piñar, la Fundación Ramiro Ledesma Ramos y la Fundación Serrano Súñer. Al ser fundaciones, las aportaciones de benefactores y socios tienen incentivos fiscales. 
res como hemos visto, las fuerzas políticas de izquierda y nacionalistas que componen la Comisión Constitucional, hacen cinco proposiciones no de ley en 2002, durante la sesión parlamentaria de 20 de noviembre, aprobadas por unanimidad, sobre las víctimas de la guerra civil y régimen franquista desaparecidas y asesinadas por defender valores republicanos, personas exiliadas y sobre exhumaciones en fosas comunes. ${ }^{11}$

Ponen en valor la Constitución de 1978 como de la concordia y como la que intentó poner fin a las dos Españas enfrentadas, asunto cerrado con la ley de Amnistía de 1977. Estas proposiciones no están en la línea de la justiciabilidad de los hechos del pasado, sino en promover cuestiones como el reconocimiento de las personas exiliadas por la guerra civil, los niños de la guerra, y las exhumaciones. Estas cinco proposiciones iban acompañadas de una declaración que supone la primera condena del franquismo y el proyecto de olvido en que se basaba la transición española. Se deja bien claro que en España no existe, ni en este momento postransicional un derecho a la memoria sino un deber de olvido consensuado por los partidos políticos.

Aunque no dice expresamente que el franquismo fue un totalitarismo, esta nomenclatura aparece en un contexto de condena al régimen. En el párrafo 2 dice que "resulta conveniente para nuestra convivencia democrática mantener el espíritu de concordia y de reconciliación que presidió la elaboración de la Constitución de 1978 y que facilitó el tránsito pacífico de la dictadura a la democracia." Finalmente, el párrafo 4 da la única medida urgente, en forma de reconocimiento económico, nacionalidad y voto parea los descendientes de las personas exiliadas durante la guerra civil.

El 14 de mayo de 2003, una Proposición no de Ley presentada en el Congreso de los Diputados pide al gobierno la eliminación de antecedentes penales por las leyes homófobas del franquismo, el traslado de la documentación relativa a archivos históricos, reconocimiento moral y reparación económica, recordando que estas personas no se beneficiaron del indulto de 1975 ni de la amnistía de $1976 .{ }^{12}$

En la sesión de 1 de junio de 2004 se aprueba una Proposición no de ley sobre el reconocimiento de las víctimas de la Guerra Civil y del franquismo, ${ }^{13}$ importante para la futura Ley de Memoria Histórica. El texto, basado en las proposiciones de 2002, insta al Gobierno a llevar un estudio que sistematice los derechos reconocidos por la legislación estatal y autonómica a las víctimas de la guerra civil, el franquismo y la Transición (entendida aquí hasta 1977), con propuestas de mejora. De este modo y en el periodo de un año se tendría que proponer

11 Boletín Oficial de las Cortes Generales VII Legislatura Serie D n 448 (29-11-2002), pp. 12-14. Disponible en: http://www.congreso. es/public_oficiales/L7/CONG/BOCG/D/D_448.PDF [Consulta: 15 de marzo de 2020].

12 Boletín Oficial de las Cortes Generales VII Legislatura Serie D n ${ }^{\circ}$ 544 (30-5-2003). Disponible en: http://www.congreso.es/public_oficiales/L7/CONG/BOCG/D/D_544.PDF [Consulta: 15 de marzo de 2020].

13 Boletín Oficial de las Cortes Generales VIII Legislatura Serie D n ${ }^{\circ}$ 31 (8-6-2004). Disponible en: http://www.congreso.es/public oficiales/L8/CONG/BOCG/D/D 031.PDF [Consulta: 15 de marzo de 2020]. una ley de solidaridad con las víctimas. La proposición también insta a facilitar el acceso a archivos.

\section{Las medidas durante la presidencia de José Luis Rodríguez Zapatero (2004-2011)}

El PSOE abre una ventana de oportunidad a las reclamaciones de las asociaciones memorialistas y partidos políticos. La primera medida llega mediante el Real Decreto 1891/2004, de 10 de septiembre, por el que se crea la Comisión Interministerial para el estudio de la situación de las víctimas de la guerra civil y del franquismo. Sería una Comisión que establezca el Estado de la cuestión de las reparaciones, tal y como se pidió en la propuesta no de ley que se hizo meses antes y de la que emanarán las propuestas legales, publicando su informe el 28 de julio de 2006, como base de la llamada Ley de Memoria Histórica. ${ }^{14}$

La Ley 3/2005, de 18 de marzo, por la que se reconoce una prestación económica a los ciudadanos de origen español desplazados al extranjero, durante su minoría de edad, como consecuencia de la Guerra Civil, y que desarrollaron la mayor parte de su vida fuera del territorio nacional, está dedicada a las niñas y niños del exilio que salieron masivamente al exterior y que siguiendo fuera o ya en España poseen pensiones bajas.

En ese mismo año, se aprueba una de las leyes más polémicas: Ley 21/2005, de 17 de noviembre, de restitución a la Generalidad de Cataluña de los documentos incautados con motivo de la Guerra Civil custodiados en el Archivo General de la Guerra Civil Española y de creación del Centro Documental de la Memoria Histórica. La ley se justifica en la aprobación del Estatuto de Cataluña que en 1932 hizo la II República, pasando competencias a esta región y a la Ley de 5 de abril de 1938 que revirtió en plena guerra civil estas funciones al Estado, incautando documentos entregados a la Delegación del Estado para la Recuperación de Documentos (DERD).

Derogada la Ley de 1938 y restituida la Generalitat en 1977 supone "el renacimiento del derecho de sus Instituciones a recuperar su memoria histórica y a la restitución de su archivo institucional, por tanto, de los documentos y efectos incautados en aquel trágico período de la historia de España", siguiendo con la exposición de motivos. Los documentos por restituir se encontraban en el Archivo General de la Guerra Civil Española en Salamanca, donde quedaría un duplicado documental, según establece el artículo 3. La disposición adicional segunda prevé la creación de un "Centro Documental de la Memoria Histórica con sede en Salamanca, en el que se integrarán los fondos del actual Archivo General de la Guerra Civil Española.’"15

\footnotetext{
4 Informe General de la Comisión Interministerial para el Estudio de la situación de las víctimas de la Guerra Civil y del Franquismo (2006). Disponible: http://www.memoriahistorica.gob.es/es-es/LaLey/Documents/InformeVictimas.pdf [Consulta: 15 de marzo de 2020].

15 Ante la ley de Zapatero se iniciaron varias medidas legales encabezadas por el Partido Popular de Castilla y León hasta que llegó la Sentencia 20/2013, de 31 de enero del Tribunal Constitucional, fallando a favor del Estado. Los documentos se conservan en el Archivo General de Cataluña.
} 
En 2005 se hacen dos proposiciones de ley publicadas en el Boletín Oficial del Estado (BOE) de 2 de diciembre. Una de ellas, titulada Sobre la memoria histórica republicana y antifascista presentada por el Grupo Parlamentario de Esquerra Republicana, alude explícitamente al golpe de Estado que derrocó a un gobierno legalmente constituido. El objetivo de la propuesta es aplicar la doctrina de las Naciones Unidas en materia de crímenes de lesa humanidad cometidos durante el franquismo, proponiendo medidas como la reparación por la diversidad de colectivos represaliados. A su vez la Proposición de Ley sobre la promoción de la recuperación y fomento de la Memoria y Cultura Democrática, del grupo parlamentario de Izquierda Verde-Izquierda UnidaIniciativa per Catalunya Verds, incide en la defensa de los ideales republicanos para proponer, entre otras medidas, un Instituto de la Memoria y Cultura Democrática.

El año 2005 termina con la disposición adicional sexagésima cuarta de la Ley 30/2005, de 29 de diciembre, sobre los Presupuestos Generales del Estado para 2006, mediante el que se aplica la "exención del pago del IRPF a las indemnizaciones recibidas por personas que, habiendo sufrido privación de libertad, se hallen en los supuestos contemplados en la Ley 46/1977, de 15 de octubre, de Amnistía".

El año 2006 será de conmemoraciones: $75^{\circ}$ aniversario de la proclamación de la Segunda República Española y el $70^{\circ}$ del comienzo de la guerra civil. La Ley 24/2006, de 7 de julio, declara este año como de la memoria histórica. Aprobada por todos los grupos políticos salvo por el PP, propone varios actos conmemorativos y culturales. La disposición adicional primera prevé que el gobierno presentará ante la Comisión Constitucional del Congreso de los Diputados, los informes elaborados por la Comisión Interministerial para el estudio de la situación de las víctimas de la guerra civil y el franquismo, constituida previamente por el Real Decreto 1891/2004, de 10 de septiembre. Es en este momento cuando hay un rescate histórico y moral de la II República como periodo democrático en el que se debía mirar la España del momento.

Destacan dos leyes más. La Ley 35/2006, de 28 de noviembre, sobre el impuesto de la renta, en cuya disposición adicional decimonovena, declara exentas las ayudas e indemnizaciones por privación de libertad como consecuencia de los supuestos contemplados en la Ley de Amnistía de 1977. Finalmente, la Ley 40/2006, de 14 de diciembre, del Estatuto de la ciudadanía española en el exterior, donde se contempla el exilio durante la guerra civil y el franquismo como "una pérdida para el desarrollo económico, cultural y social de España”, en la exposición de motivos I. A estas personas se conceden una serie de derechos de participación, reconocimientos administrativos y económicos. La ley reconoce el impacto diferencial del exilio sobre las mujeres, en la exposición de motivos I.9.

El año 2007 será crucial para la memoria histórica. En primer lugar, el Real Decreto 697/2007 de 1 de junio, crea el Centro Documental de la Memoria Histórica. En este Centro se integra el Archivo de la Guerra Civil Española y seguirá estando en Salamanca, según el artículo
1 , teniendo entre sus funciones "asesorar y cooperar en la localización de información para la reparación de la memoria y ayuda a las víctimas de la represión" en base al artículo 2.e.

A finales de año se aprobaba la Ley 52/2007, de 26 de diciembre, por la que se reconocen y amplian derechos y se establecen medidas en favor de quienes padecieron persecución o violencia durante la guerra civil y la dictadura, conocida como "Ley de Memoria Histórica". Impulsada especialmente por PSOE, Izquierda Unida y Esquerra Republicana de Catalunya y criticada por el Partido Popular, que votó en contra. Fue el fruto de grandes debates entre el PP, que la consideraba innecesaria y los grupos de izquierda y nacionalistas que la consideraban insuficiente. ${ }^{16}$ Finalmente, se aprobaría la ley con el voto negativo del Partido Popular y de Esquerra Republicana de Catalunya.

En la exposición de motivos, la ley se hace eco de las "peticiones legítimas y justas" planteadas por partidos políticos y asociaciones cívicas. Alude a la proposición no de ley de 2002 y asume la Recomendación 1736 (2006) de la Asamblea Parlamentaria del Consejo de Europa, con la condena internacional del Régimen de Franco y sus violaciones de derechos humanos. Deja claro que esta ley es inicial en sentido de sentar: "las bases para que los poderes públicos lleven a cabo políticas públicas dirigidas al conocimiento de nuestra historia y al fomento de la memoria democrática. [...] Parte de la consideración de que los diversos aspectos relacionados con la memoria personal y familiar [...], forman parte del estatuto jurídico de la ciudadanía democrática." Esta insistencia a la memoria personal parece una despolitización de la memoria que entra en choque con medidas reparatorias y con lo que debería ser una verdadera política pública.

En el artículo 1 se afirma que el objeto de la ley es: "Reconocer y ampliar derechos a favor de quienes padecieron persecución o violencia, por razones políticas, ideológicas, o de creencia religiosa, durante la Guerra Civil y la Dictadura, promover su reparación moral y la recuperación de su memoria personal y familiar." Así como el conocimiento de los hechos del pasado y su conservación archivística. En el artículo 2 sobre el derecho: "se reconoce y declara el carácter radicalmente injusto de todas las condenas, sanciones y cualesquiera formas de violencia personal". Pero no se anulan estas condenas ilegítimas generadas durante la guerra civil y el franquismo. La única medida ante esto se encuentra en el artículo 4, que ofrecía una declaración de reparación y reconocimiento personal a quienes fueron sentenciados en tal contexto.

Los artículos 5 a 10 reconocen y mejoran prestaciones de pensiones, a viudas, a huérfanos, a hijos de fallecidos y a presos. Se establecerán planes de trabajo y subvenciones para las exhumaciones como se ve en los artículos 12, 13 y 14, comprometiéndose a una colaboración económica con las asociaciones memorialistas, pero no como

16 Diario de Sesiones del Congreso de los Diputados del 31 de octubre de 2007, pp. 14615 y ss. Disponible en: http://www.congreso. es/public_oficiales/L8/CONG/DS/PL/PL_296.PDF [Consulta: 15 de marzo de 2020]. 
una obligación estatal. Los artículos 15, 16 y 17 abordan la cuestión de los símbolos y monumentos de exaltación franquista que deberán ser retirados por las Administraciones Públicas, la retirada de subvenciones y ayudas públicas, incluyendo el Valle de los Caídos. El artículo 20 crea el Centro Documental de la Memoria Histórica y Archivo General de la Guerra Civil. El artículo 21 promueve la adquisición y protección de documentos sobre la Guerra Civil y la Dictadura, así como el derecho, en el artículo 22, al acceso a los fondos documentales depositados en los archivos públicos y privados.

La ley se desarrollará por varias normativas. La $\mathrm{Or}$ den del Ministerio de la Presidencia 3189/2008, de 31 de octubre de 2008, por la que se publica el Acuerdo de Consejo de Ministros, de 31 de octubre de 2008, donde se toma conocimiento de las medidas de desarrollo de la Ley 52/2007, de 26 de diciembre ${ }^{17}$, con las siguientes medidas: obtención de la nacionalidad española a los hijos nacidos en el extranjero por personas exiliadas, acceso a los libros de actas de defunciones de los Registros Civiles, elaboración del Protocolo de actuación científica multidisciplinar para la realización de las exhumaciones, y la elaboración de un mapa donde se localicen restos de las víctimas.

El Real Decreto 1803/2008, de 3 de noviembre, por el que se regulan las condiciones y el procedimiento para el abono de las indemnizaciones reconocidas en la Ley 52/2007, de 26 de diciembre, a favor de personas fallecidas o con lesiones incapacitantes por su actividad en defensa de la Democracia. Del mismo año son las siguientes Instrucciones del Ministerio de Justicia: Instrucción de 4 de noviembre de 2008, de la Dirección General de los Registros y del Notariado, sobre el derecho de opción a la nacionalidad española establecido en la disposición adicional séptima de la Ley 52/2007, de 26 de diciembre. Y la Instrucción de 4 de noviembre de 2008, de la Dirección General de los Registros y del Notariado, sobre acceso a la consulta de los libros de defunciones de los registros civiles, dictada en desarrollo de la disposición adicional octava de la Ley 52/2007, de 26 de diciembre.

Dentro del Ministerio de Justicia se regulan dos reales decretos: Real Decreto 1791/2008, de 3 de noviembre, sobre la declaración de reparación y reconocimiento personal a quienes padecieron persecución o violencia durante la Guerra Civil y la Dictadura, que desarrolla el artículo 4 de la Ley de Memoria Histórica. Y Real Decreto 1792/2008, de 3 de noviembre, sobre concesión de la nacionalidad española a los voluntarios integrantes de las Brigadas Internacionales, que deroga el Real Decreto 39/1996, de 19 de enero que tenía el mismo objeto. Por su parte, el Ministerio de Trabajo y Asuntos Sociales se encarga de gestionar lo dispuesto en el Real Decreto 8/2008, de 11 de enero, regulando la prestación a favor de los españoles residentes en el exterior y retornados, contemplado en el artículo 19 de la Ley 40/2006, de 14 de diciembre.

17 También en el I Plan de Derechos Humanos de España (2008-2012) se prevé el desarrollo de la ley en las medidas 86 y 87 . Disponible en: http://www.ohchr.org/Documents/Issues/NHRA/Spain_NHRAP. pdf [Consulta: 15 de marzo de 2020].
El año 2008 seguirá con los desarrollos normativos, ya que se creará la Oficina para las Víctimas de la Guerra Civil y de la Dictadura, dependiente de la Subsecretaría del Ministerio de Justicia y regulada mediante la Orden 3749/2008, de 22 de diciembre emanada del Acuerdo del Consejo de Ministros de 19 de diciembre de 2008 e incluida en el Plan de Derechos Humanos aprobado el 12 de diciembre de ese año. El objetivo era servir de información ante la Ley de Memoria Histórica y coordinar las exhumaciones.

Debemos destacar que en este año se aborda diferencialmente la problemática de los ex presos sociales, incluyendo a las disidencias sexuales represaliadas durante el franquismo, mediante la Ley 2/2008 de 23 de diciembre, de Presupuestos Generales del Estado para el año 2009, en su disposición adicional decimoctava. Incluyendo a las víctimas o ante el fallecimiento de estas, a los cónyuges, esta ley se desarrollará mediante el Real Decreto 710/2009, de 17 de abril en materia de pensiones e indemnizaciones, concretamente en los artículos 17 a 22 del Título II. El impacto social y laboral que para estas personas tuvo la fuerte represión franquista, sólo ha tenido esta medida específica, una ley que supo a poco en lo económico y simbólico. Además, estaba acotada temporalmente hasta el 31 de diciembre de 2013 como plazo para solicitar las indemnizaciones.

Finalmente, hay que mencionar que en este año se firma la Orden del Ministerio de Cultura 3190/2008, de 6 de noviembre, por la que se publica el Acuerdo del Consejo de Ministros, de 31 de octubre de 2008, donde se dictan instrucciones para la retirada de símbolos franquistas en los bienes de la Administración General del Estado y sus organismos públicos dependientes, desarrollando el artículo 15 de la Ley de Memoria Histórica. Meses después, una nueva Orden del Ministerio de Cultura 459/2009, de 19 de febrero crea una Comisión Técnica de Expertos para valorar los símbolos franquistas. La Comisión tuvo un alcance de los monumentos de carácter estatal. Para el resto, la medida se debía aplicar bajo competencias locales que, en muchas ocasiones tienen reticencias a cumplir la normativa.

En 2009 continúan las medidas, el Real Decreto 2134/2008, de 26 de diciembre, por el que se regula el procedimiento a seguir para la restitución a particulares de los documentos incautados con motivo de la Guerra Civil. Basándose en la Ley 21/2005, de 17 de noviembre, sobre la devolución de documentos incautados durante el franquismo a la Generalitat de Catalunya, donde se establece que las personas naturales o jurídicas podrán solicitar a las comunidades autónomas documentos incautados, dejando copia (auténtica) o duplicado en el Centro Documental de la Memoria Histórica, según el artículo 5.4. ${ }^{18}$ La Orden del Ministerio de la Presi-

18 Esta devolución documental de bienes incautados a personas físicas no se traducirá en el reclamo de devolución de bienes inmuebles incautados, como ya se hizo con partidos políticos y sindicatos. Así, en la Sentencia del Tribunal Supremo (Sala $3^{\text {a }}$ ) de 5 de abril de 2006, Ponente Sr. Manuel Campos Sánchez-Bordana, se establece la falta de legitimación de los particulares en base a la Ley 43/1998 para reclamar sus bienes confiscados. 
dencia 3279/2009, de 4 de diciembre, que reconoce a miembros de las Fuerzas Armadas favorables a la democracia como la Unión Militar Democrática. La Ley 26/2009, de 23 de diciembre, de Presupuestos Generales del Estado para el año 2010, en su disposición adicional sexagésima hace una nueva modificación del artículo 10 de la Ley de Memoria Histórica, esta vez en su párrafo 2 , que amplía los familiares beneficiarios en el caso de víctimas fallecidas. Finalmente, ese año, el Real Decreto 2005/2009, de 23 de diciembre, en su disposición adicional primera, revaloriza y actualiza pensiones para víctimas y familiares para 2010 .

El año 2010 estará marcado de manera más evidente por la crisis económica y el desencanto social, algo que se deja notar en las normativas de memoria. Se destaca el Real Decreto 1816/2009, de 27 de noviembre, por el que se aprueba el Reglamento de los Archivos Judiciales Militares, que no se publicará en el BOE hasta enero de 2010. Mediante esta normativa se habilita el acceso documental, en base al artículo 22 de la Ley de Memoria Histórica. Finalmente está la Resolución de 17 de marzo de 2010, de la Subsecretaría, por la que se dispone la publicación del Acuerdo del Consejo de Ministros de 22 de enero de 2010, por el que se amplía un año el plazo para ejercer el derecho de optar a la nacionalidad española recogido en la disposición adicional séptima de la Ley 52/2007. de 26 de diciembre.

El año siguiente nos encontramos la Orden del Ministerio de la Presidencia 2568/2011, de 26 de septiembre, por la que se publica el Acuerdo del Consejo de Ministros de 23 de septiembre de 2011, donde se ordena la publicación en el Boletín Oficial del Estado del Protocolo de actuación en exhumaciones de víctimas de la guerra civil y la dictadura, con el fin de solventar la ausencia de protocolos autonómicos en este sentido. En desarrollo del artículo 16 y la disposición adicional sexta de la Ley de Memoria Histórica sobre el Valle de los Caídos que determinan el sitio como lugar de culto y cementerio público, prohibiendo actos de exaltación de la Guerra Civil, sus protagonistas, o del franquismo, e instando a convertirlo en lugar de memoria colectiva democrática se dicta la Orden del Ministerio de la Presidencia 1396/2001, de 27 de mayo, por la que se publica el Acuerdo del Consejo de Ministros donde se crea la Comisión de Expertos para el Futuro del Valle de los Caídos. El informe de la Comisión fue publicado el 29 de noviembre de 2011, manifestando entre otras cuestiones la diversidad de las victimas enterradas, el impedimento que suponen los enterramientos de Franco y Primo de Rivera que deberían ser trasladados, la necesidad de resignificar el conjunto sin destruir, o el carácter inviolable de la basílica que está en el conjunto, ya que sigue bajo custodia de la orden benedictina. ${ }^{19}$

\footnotetext{
19 Informe de la Comisión de Expertos sobre el Futuro del Valle de los Caídos (2011). Disponible en: http://www.memoriahistorica.gob.es/ es es/vallecaidos/Documents/InformeComisinExpertosValleCados. pdf [Consulta: 15 de marzo de 2020].
}

\section{Las medidas durante la presidencia de Mariano Rajoy (2011-2018)}

En diciembre de 2011 el PP vuelve a ocupar el gobierno liderado por Mariano Rajoy. En estos momentos los logros de la Ley de Memoria Histórica comienzan a desvanecerse por la crisis económica y por la falta de voluntad política. Los presupuestos generales del Estado para 2012 dedicados a esta Ley se redujeron un 60\% y la Oficina de Víctimas de la Guerra Civil y la Dictadura a cargo de la coordinación de las exhumaciones fue suprimida. Esta fue la última dotación económica, que desapreció en los siguientes presupuestos. Sólo en 2012 se dicta la Orden del Ministerio de Justicia 2146/2012, de 1 de octubre, por la que se crean determinados ficheros de datos de carácter personal relacionados con los supuestos de posible sustracción de recién nacidos.

\section{Los nuevos gobiernos de izquierda desde $\mathbf{2 0 1 8}$}

Tras una moción de censura el 1 de junio de 2018, se produce un cambio de gobierno liderado por el PSOE de Pedro Sánchez. Esto hace que se retome la Ley de Memoria Histórica y las políticas de memoria vuelvan a estar sobre la agenda, con una Dirección General para la Memoria Histórica dentro del Ministerio de Justicia. El grupo socialista ya registró en 2017 la Proposición de Ley para la reforma de la Ley 52/2007, de "Memoria Histórica”, publicado en el BOE no 310 de 22 de diciembre. Propone la anulación de las sentencias franquistas, la creación de una Comisión de la Verdad, censo nacional de víctimas, reparaciones económicas, la exhumación como plena responsabilidad del Estado, la búsqueda judicial de las personas desaparecidas incluyendo los menores sustraídos. Es una propuesta que sí incorpora la transversal de género y diversidad afectivo-sexual de manera explícita. Es destacable que en el artículo 2 hacen algunas definiciones, y la referente a justicia, en el contexto de esta propuesta legal, se entiende como investigar y no incriminar. Con lo cual está más cerca del derecho a la verdad, difiriendo de la doctrina internacional. Las siguientes propuestas legales del PSOE, cuando esté en el gobierno, serán más tímidas en verdad y justicia.

Por su lado, el Grupo Parlamentario de Unidas Podemos —En Comú Podem - En Marea presentó también una Proposición de ley sobre la reforma de la Ley 52/2007, publicada en el BOE de 12 de enero de 2018. Más breve que la socialista, revisa algunas cuestiones como la nulidad de sentencias o responsabilidad del Estado para localizar e identificar las víctimas. También presenta una Ley integral de memoria democrática y de reconocimiento y reparación a las víctimas del franquismo y la Transición, recogida en el BOE de 13 de julio de 2018. En esta propuesta hay una mayor presencia de la justicia penal, buscando al victimario y no simplemente en la investigación y localización de la víctima cuando, por ejemplo, esté desaparecida, como proponía la reforma legal del PSOE. Más extensa y completa que la socialista, inciden de manera más detallada en las víctimas 
por razón de género y diversidad afectivo-sexual. Tanto esta propuesta como la socialista incorporarán un bloque de sanciones con propuestas de modificación del Código Penal o de la Ley del Estatuto de la víctima del delito.

Como complemento de las anteriores, que se hacen eco del tema, en el BOE de 5 de octubre de 2018 se publica la Proposición de Ley sobre bebés robados en el Estado español. Presentada por los Grupos Parlamentarios Confederal de Unidas Podemos-En Comú Podem-En Marea, de Esquerra Republicana, Socialista y Diputados del Grupo Parlamentario Mixto. En esta propuesta, la primera estatal, se establece el marco temporal desde el 17 de julio de 1936 sin fecha de cierre, dada la prolongación de este delito de desaparición forzada de menores en las postrimerías del franquismo y la Transición. Contempla el derecho de acceso a todo tipo de archivos; la creación de una fiscalía especializada que actuará de oficio, la gratuidad de las exhumaciones y las pruebas de ADN; y la conformación de una Comisión Estatal por el derecho a la Identidad entre otras medidas. Por primera vez, todos los grupos aprobaron unánimemente la tramitación de esta proposición de ley, quizá al ser una cuestión que va más allá de los límites del franquismo. En el BOE del 6 de marzo de 2019 se publican las enmiendas y el BOE de 6 de marzo de 2020 vuelve a presentar la propuesta legal.

Con carácter de urgencia, se creó mediante el artículo 11 del Real Decreto 1044/2018 de 24 de agosto, la Dirección General para la Memoria Histórica, dentro del Ministerio de Justicia con dos órganos: la Subdirección General de Ayuda a las Víctimas de la Guerra Civil y de la Dictadura, y la División de Coordinación Administrativa y Relaciones Institucionales. Pero quizá la medida más polémica, es el Real Decreto-Ley 10/2018, de 24 de agosto que añade un apartado 3 al artículo 16 de la Ley 52/2007, con la siguiente redacción: “en el Valle de los Caídos sólo podrán yacer los restos mortales de personas fallecidas a consecuencia de la Guerra Civil española, como lugar de conmemoración, recuerdo y homenaje a las víctimas de la contienda". Declaran esta medida como "de urgente y excepcional interés público, así como de utilidad pública e interés social." Se acompañaba de una disposición adicional sexta en la citada ley para procedimentar esta modificación. Esto implica la exhumación y traslado de los restos de Franco, dada la anomalía democrática que supone tener sepultado a un dictador en un lugar de culto que recibe fondos públicos.

Tras la moción de censura que posibilitó el gobierno del PSOE se producen dos elecciones generales: el 28 de abril de 2019, ganado el PSOE, pero sin capacidad para formar gobierno, lo que derivó en unas nuevas elecciones, el 10 de noviembre de 2019, en las que volvió a ganar el PSOE de Pedro Sánchez, conformando un gobierno de coalición con Unidas Podemos. Estas dos elecciones tienen una consecuencia fundamental y es que entra en el Congreso el partido Vox (52 diputados), contrario a las políticas de memoria y a toda condena del franquismo. Por su lado, el gobierno de coalición dará un nuevo organigrama institucional a la memoria. Se crea un Ministerio de la Presidencia, Relaciones con las Cortes y Memoria Democrática y el Real Decreto 373/2020, de 18 de febrero establece una Secretaría de Estado de Memoria Democrática, de la que depende una Dirección General de Memoria Democrática, con competencia para elaborar un Plan Estatal de Memoria Democrática.

Entre un proceso electoral y otro, el Grupo Parlamentario Socialista hace una Proposición de Ley de Memoria Histórica y Democrática, publicada en el BOE del 30 de julio de 2019. Con un texto más sintético que la propuesta de modificación de ley presentada por el mismo Grupo en 2017. En la exposición de motivos destaca la necesidad de tener una política de Estado sobre memoria histórica, que vaya más allá de la tendencia ideológica del gobierno. La propuesta legal vuelve a recalar en las exhumaciones, creación de banco de ADN y censo de víctimas, la creación de un Consejo de la Memoria como órgano consultivo y participativo, medidas de educación e investigación considerando diferencialmente a las mujeres represaliadas, acciones de reparación simbólica, así como la revocación de recompensas y condecoraciones a agentes de seguridad franquistas. Finalmente, esta propuesta hace una serie de disposiciones para modificar la Ley 52/2007, proponiendo la nulidad de sanciones franquistas, la responsabilidad del Estado de exhumar y buscar a las personas desaparecidas, el Valle de los Caídos o el acceso a archivos. También introduce una modificación a la Ley 15/2015 sobre la Jurisdicción Voluntaria, referente a las declaraciones judiciales sobre hechos pasados.

Los últimos meses de 2019 y los primeros de 2020 han tenido varias propuestas de memoria. Quizá la principal sea la exhumación del dictador Francisco Franco del Valle de los Caídos para reinhumarlo el 24 de octubre de 2019 en el panteón que la familia tiene en el cementerio de Mingorrubio en la localidad de El Pardo. En base a un informe del Consejo Superior de Investigaciones Científicas (CSIC) ${ }^{20}$ Patrimonio Nacional autorizó en noviembre de 2019 la exhumación de las víctimas de la guerra civil inhumadas en la basílica del Valle de los Caídos para las familias que lo soliciten. También hay intención de sacar a la comunidad benedictina del Valle, para resignificar el monumento; e incluir la apología del franquismo como delito en el Código Penal.

El 30 de diciembre de 2019 el PSOE y Unidas Podemos firman un acuerdo de coalición que posibilita la formación de gobierno. ${ }^{21}$ El subapartado 5.4 del acuerdo se refiere a la recuperación de la memoria democrática en forma de reconocimientos y conmemoraciones a las víctimas de la guerra civil y la dictadura; un programa de exhumaciones; eliminación de la simbología franquista del espacio público y prohibiendo la exaltación y enaltecimiento del franquismo en lugares de acceso público; retirar condecoraciones y prestaciones conce-

20 Inspección del estado de seis criptas laterales y de los niveles de las criptas del trasdós de las capillas del Santísimo y del Sepulcro de la Basílica del Valle de los Caídos. Disponible en: https://www. patrimonionacional.es/sites/default/files/2019-11/informe_del_iccet_vc.pdf [Consulta: 15 de marzo de 2020].

21 Coalición progresista. Un nuevo acuerdo para España. Disponible en: https://www.psoe.es/media-content/2019/12/30122019Coalici\%C3\%B3n-progresista.pdf [Consulta: 15 de marzo de 2020]. 
didas a personas que protagonizaron actos criminales no juzgados durante el franquismo; declarar nulas las condenas y sanciones del franquismo; y auditar los bienes expoliados por el franquismo para devolverlos a sus legítimos titulares.

Podemos decir que estos son los mínimos consensos programáticos pactados por ambos partidos políticos que obedecen más a la línea más conservadora del PSOE respecto a la memoria democrática, que a la progresista de Unidas Podemos con medidas más integrales incluyendo, por ejemplo, la justicia penal. Esto quiere decir que las políticas de memoria están bajo el mandato socialista. En línea con lo anterior, el Grupo Parlamentario Socialista presenta de nuevo la Proposición de Ley de Memoria Histórica y Democrática, publicada en el BOE de 31 de enero de 2020, donde insiste en realizar una política de Estado respecto a las cuestiones de memoria. Quizá por eso y para conseguir un consenso, la propuesta se muestra menos innovadora que las anteriores. De hecho, es prácticamente la misma que la presentada en julio de 2019, para poder sacarla adelante en este nuevo gobierno.

\section{Conclusiones}

1. Legalmente, España está instalada en una "impunidad absoluta con indemnización a las víctimas". Esta situación se desprende de una transición a la democracia que no rompió con el franquismo, en el presunto consenso social y político de una mítica Transición idílica y en la Ley de Amnistía que genera impunidad.

2. La situación anterior genera unas medidas dirigidas principalmente a la reparación económica y simbólica, a algunas medidas de no repetición relacionadas con la educación y sensibilización, pero no a medidas relacionadas con la verdad y la justicia en sentido integral.

3. Las medidas adoptadas desde el gobierno central han sido dispersas e ideologizadas. La transversalidad y multidisciplinariedad de las políticas de memoria y lucha contra la impunidad hace que no sea sólo una competencia del gobierno central, sino en ocasiones de la administración autonómica y local, lo que dificulta aún más su ejecución.

4. Es difícil establecer una política de Estado sobre memoria, ya que el PP es un partido que surge del franquismo y Vox se puede considerar una escisión de extrema derecha con vínculos ideológicos franquistas. Por su lado, el PSOE se muestra favorable hacia políticas de reparación, pero reacio a proponer medidas de derecho a la verdad como comisiones a la verdad y menos sobre el derecho a la justicia, rompiendo con la Ley de Amnistía. Para Ciudadanos, un partido que ha realizado pactos con PP y Vox, no es una prioridad política. Unidas Podemos y su coalición de izquierdas, así como algunos partidos nacionalistas son los que se muestran más alineados con las demandas sociales y las peticiones de organismos internacionales, como los ór- ganos de tratados de derechos humanos del sistema de Naciones Unidas.

5. Las primeras medidas, emanadas de uno de los partidos que salió del franquismo, la UCD y de la Ley de Amnistía de 1977, se refieren a indultos y compensación económica de las personas damnificadas de la guerra civil, sin la más mínima condena al régimen franquista, ni alusiones a la II República derrocada por un golpe de estado.

6. Hasta 1980 no se produce la primera reparación económica diferenciada hacia excombatientes de la zona republicana, la Ley 35/1980. Con el gobierno socialista entre 1982 y 1986 esta tendencia continuó reparando económicamente a personas que sufrieron prisión, carabineros de la II República, la Unión Militar Democrática, Brigadas Internacionales o exiliados.

7. Debemos destacar que durante el gobierno del PP entre 1996 y 2004, no progresaron las medidas reparatorias, pero sí se puede desatacar que hubo otro tipo de medidas económicas de apoyo a fundaciones cuyo objetivo es mantener y difundir la memoria franquista. Pero es justo en este periodo, que podemos considerar postransicional, cuando la sociedad civil se organiza y visibiliza más, se apoya en organizaciones internacionales y hace incidencia a partidos políticos para pasar de meras reparaciones a políticas de memoria con un carácter más integral.

8. Con el PSOE de Rodríguez Zapatero en el gobierno entre 2004 y 2011 se producen los primeros frutos y se puede hablar de la primera Ley de Memoria Histórica, la Ley 52/2007, prescindible para el PP e insuficiente para partidos nacionalistas. En definitiva, incidía básicamente en reparaciones económicas y simbólicas, tratando parcialmente el derecho a la verdad y omitiendo la justicia.

9. Tras un nuevo gobierno del PP entre 2011 y 2018, la ausencia de voluntad política y la crisis económica dejan sin funcionamiento la Ley 52/2007.

10. Con la moción de censura de 2018 y el gobierno de coalición entre PSOE y Unidas Podemos, se han retomado de nuevo las medidas memorialistas, pero bajo la influencia más moderada del socialismo. Veremos en esta XIV Legislatura si finalmente se aprueban las nuevas propuestas legales sobre memoria democrática y bebés robados. La primera sigue las medidas de reparación simbólica y económica, apostando también por las exhumaciones, pero sin medidas fuertes en derecho a la verdad, como la creación de una comisión de esclarecimiento y menos en justicia. El proceso de debate y enmiendas determinarán el futuro de la memoria democrática en España.

11. La Ley 52/2007 supuso un hito en la historia de España, pero se situaba en un incómodo centro buscando un consenso que nunca llegó. Si prospera la nueva propuesta socialista, supondrá un nuevo avance que no satisface ni a los reclamos sociales ni a los internacionales sacrificados en pro de un nuevo supuesto consenso y de una política de Estado que, sea como fuere, resulta improbable ante la negativa de los partidos de derecha ante estas políticas memorialistas. Con lo cual ¿es mejor volver a una ley atemperada 
de consensos o aprovechar la colación progresista en el gobierno para presentar una ley más acorde con reclamos sociales e internacionales? En cualquier caso, tener la posibilidad de volver a plantear leyes y políticas memorialistas es todo un logro.

12. Debemos destacar al fuerte movimiento social memorialista de España, que en consonancia con diversos órganos e instrumentos de Naciones Unidas hace labor de incidencia política y movilización social, impulsando nuevas leyes, apoyando a las víctimas y estando donde el Estado no está: ARMH, Coordinadora de Apoyo a la Querella Argentina (CEAQUA), Plataforma por la Comisión de la Verdad, Asociación de la Memoria Social y Democrática (AMESDE), la Comuna de lxs presxs del franquismo, Todos los niños robados son también mis niños, etc. Son muchas más, es imposible mencionarlas aquí a todas, pero sería interesante que se constituyesen en una Coordinadora Estatal para la Memoria Democrática en España.

13. Finalmente una conclusión que sintetice las medidas necesarias - algunas incluidas en las últimas proposiciones legales analizadas-, para que España cumpla con los estándares internacionales contra la impunidad en materia de justicia transicional y memoria democrática: derogar, modificar o interpretar la Ley
46/1977 para abrir la vía jurídica, investigando, recopilando declaraciones, estableciendo responsabilidades penales, y creando una fiscalía específica; anular los procedimientos judiciales y sanciones del franquismo; el Estado es responsable de la localización, exhumación e identificación de las personas desaparecidas, incluyendo a los bebés robados; creación de una Comisión de la Verdad; retirar la simbología franquista y resignificar monumentos en clave de memoria democrática; apertura de los archivos públicos y privados con información sobre la guerra civil y el franquismo; formación al personal funcionarial sobre memoria democrática; inclusión específica y transversal de la memoria democrática en planes de estudio de todas las etapas educativas así como el fomento de la investigación; reparación simbólica, económica y patrimonial a las víctimas; luchar desde una reforma del código penal contra la apología del franquismo y las organizaciones fascistas propensas al discurso y delitos de odio. Todas estas medidas deberían tener su reflejo orgánico en la administración central, coordinando con las autonomías y la sociedad civil. Además, deberían incorporar el enfoque de derechos humanos, género y diversidad para procurar la máxima inclusión y las medidas positivas apropiadas.

\section{Bibliografía}

Aguilar Fernández, P. (1996). Memoria y olvido de la Guerra Civil Española. Madrid: Alianza Editorial.

Aguilar Fernández, P. (2008). Políticas de la memoria y memorias de la política. Madrid: Alianza Editorial.

Santos, J. (1999). Un siglo de España. Política y sociedad. Madrid: Marcial Pons.

Mate, R. (2011). Tratado de la injusticia. Barcelona: Anthropos.

Muñoz de Córdoba, M. Á. (2009). Reflexiones en torno a nuestro pasado reciente. España, los años 30 del siglo XX. Madrid: Cultiva Libros.

Ruiz, D. (2002). La España democrática (1975-2000). Política y sociedad. Madrid: Síntesis.

Sánchez-Moreno, M. (2019a). Desalmadas y maleantes. Memoria de género en Argentina y España (1936-2018). Málaga: Editorial UMA.

Sánchez-Moreno, M. (2019b). "Memoria e historia: una aproximación internacional desde el ámbito jurídico", en Amnis, n 18. Disponible en: http://journals.openedition.org/amnis/4390 (Consulta, 15 de marzo de 2020). 